\title{
Transfollicular drug delivery: current perspectives
}

This article was published in the following Dove Press journal:

Research and Reports in Transdermal Drug Delivery

20 April 2016

Number of times this article has been viewed

\section{Amit Verma \\ Ankit Jain \\ Pooja Hurkat \\ Sanjay K Jain}

Pharmaceutics Research Projects Laboratory, Department of Pharmaceutical Sciences, Dr Harisingh Gour University, Sagar, Madhya Pradesh, India
Correspondence: Sanjay K Jain Pharmaceutics Research Projects Laboratory, Department of Pharmaceutical Sciences, Dr Harisingh Gour University, University Road, Sagar, Madhya Pradesh 470003, India

$\mathrm{Tel}+917582265457$

$\mathrm{Fax}+917582264163$

Email drskjainin@yahoo.com
Abstract: The pilosebaceous unit is the collective form of a hair follicle, hair shaft, and sebaceous gland. Within the skin, this three-dimensional composite shows a distinctive biochemistry, metabolism, and immunology. Presently, most researchers in this area are focused on the hair follicles, as they see these as a potential pathway for both localized and systemic delivery of various chemotherapeutics. Better understanding of the configuration of the hair follicle is mulled over in order to design rational drug formulations to achieve targeted follicular delivery. Targeted drug delivery may enhance the efficacy of current therapeutics to treat diseases of follicular origin. The present review covers follicular drug delivery with the potential to target the pilosebaceous unit.

Keywords: pilosebaceous unit, hair follicle, sebaceous gland, topical drug delivery

\section{Introduction}

Transdermal delivery has great potential to deliver drugs continuously into the systemic circulation, thereby circumventing first-pass metabolism. However, when focusing on drug delivery to specific areas in the skin, such as the hair follicle and sweat and sebaceous glands, application of the drug on the skin surface demands a more selective approach to increase the drug concentration at the site of action. For many decades, scientists experimenting on human skin have questioned the relative significance of drug transport via the stratum corneum (SC) against penetration of the drug through the follicular shunts of the pilosebaceous units. Initial experimentations revealed a minute role of follicles in achieving a steady state in drug permeation, which was contradicted. ${ }^{1}$ This was illustrated by qualitative studies of dye and stain localization in the hair follicles, specifically offering confirmation of penetrant buildup, ${ }^{2}$ while maximum absorption was shown by the some compounds in the region of maximum follicular densities. ${ }^{3,4}$

The SC is a primary barrier to percutaneous absorption. It is also considered the major route for various drugs or biomolecules penetration. Recent reports demonstrated that the transepidermal route, hair follicles, and sebaceous glands significantly contribute to topical or transdermal delivery. Below the skin surface, the hair follicles provide a large surface area for potential absorption of drugs or compounds, because of an enfolding of the epidermis extending deeply into the dermis. ${ }^{5}$

Sebaceous glands associated with the hair follicles secrete sebum, which may in return manipulate absorption by providing a lipoidal pathway. ${ }^{6}$ However, this is difficult to prove, because the most of the follicle-rich parts are also associated submit your manuscript | www.dovepress.com

Dovepress

http://dx.doi.org/1 0.2147/RRTD.S75809
Research and Reports in Transdermal Drug Delivery 2016:5 I-I7

(c) (i) (5) 2016 Verma et al. This work is published and licensed by Dove Medical Press Limited. The full terms of this license are available at https://www.dovepress.com/terms. cC) you herebby accept the Terms. Non-commercial uses of the work are permitted without any further permission from Dove Medical Press Limited, provided the work is properly attributed. For permission for commercial use of this work, please see paragraphs 4.2 and 5 of our Terms (https.//www.dovepress.com/terms.php). 
with small corneocytes, which would affect nonfollicular absorption. Moreover, the detailed nature of pilosebaceous transport mechanisms has yet to be established. Recently, various studies have supported follicular drug penetration in the delivery of therapeutics, which is contradictory to previous assumptions..$^{7-9}$ At the end of the 20th century, scientists working on skin delivery expressed two different opinions. One group favored the transfollicular route for drug delivery, but the other group said that the available surface area was simply too small to be of any relevance. Cosmetic scientists consider transfollicular applications for their products to be of great relevance. Therefore, the transfollicular route would be useful for effective delivery of antiacne products that are targeted to pilosebaceous units, antiperspirant products delivered to eccrine glands, or macromolecules (such as peptides and hyaluronic acid). For delivery of such product(s), the SC shows reluctance to allow penetration through the skin.

With time, transfollicular delivery research became stagnant, and this led scientists to agree with the initial view of Scheuplein, who in 1967 wrote that the transfollicular pathway was limited to the early phase of skin permeation, before steady-state diffusion is accomplished. ${ }^{1}$ During the early 1990s, Hueber et al concluded that human skin appendages, (hair follicles and sebaceous glands) formed a penetration path for steroids and other chemical molecules of similar molecular weight and characteristics. ${ }^{10}$ Another approach tried to analyze the participation of the infundibulum in overall skin delivery.

Penetration of chemicals/drugs via skin of newborn (24 hours old) rats was compared with 5-day-old rat skin. In vitro penetration of hydrocortisone through skin from rats killed at 24 hours and 5 days after birth was compared. These studies showed that skin penetration was fivefold greater in the presence of intact follicular units. ${ }^{11} \mathrm{~A}$ less popular method of evaluating the impact of the transfollicular route on skin delivery was to test the penetration of the same compounds in like formulations through the skin of different body sites with varying hair-follicle densities, then assigning the found differences in permeation to the participation of additional hair follicles. Rolland et al reported the significance of size in transfollicular delivery of drugs and chemicals. Researchers demonstrated that polymeric microspheres ( 3 and $7 \mu \mathrm{m}$ ) penetrated exclusively through the transfollicular route; however, whether this was real penetration or accumulation into the pilosebaceous unit and deeper dermal tissues could not be demonstrated. ${ }^{12}$

\section{Basic structure of skin}

Insight into anatomical, physiological and chemical properties of the skin is required for the knowledge of basic features of skin. Skin basically consists of four layers: 1) the SC (nonviable epidermis), 2) viable epidermis, 3) dermis, and 4) subcutaneous tissues (Figure 1). ${ }^{13}$ Apart from these layers, it also has numerous allied appendages: hair follicles, sweat glands, apocrine glands, and nails. The innermost layer is subcutaneous tissues, which are made up from connective fibers and fat. This layer serves as an insulator, a shock absorber, depot of calories, and supplier of required nutrients for more superficial skin layers. The base of hair follicles and secretory duct of sweat glands and cutaneous nerves, as well as networks of lymph and blood vessels, are also located in this area. The nature of the dermis is a fibrous layer that holds up and reinforces the epidermis. Its thickness ranges from 2 to $3 \mathrm{~mm}$, and is comprised of a loose connective tissue matrix that is composed of collagen (a fibrous protein, embedded in a semigel matrix that contains water, various ions, and mucopolysaccharides). This matrix facilitates the holding of cells, and allows oxygen and nutrients to diffuse into the epidermal cells. This layer has hair follicles, sebum and sweat glands, and an extensive blood supply and nerve network. ${ }^{14}$ The neighboring layer of the dermis is identified as the papillary layer, which offers nutritional support to the viable epidermis. The papillary layer shows an important role not only in a nutritional function but also in temperature, pressure, and pain regulation. Additionally, it contains various cells in a sparse cell population: fibroblasts, responsible for the connective tissue synthesis; mast cells, involved in the immune and inflammatory responses; and melanocytes, involved in the production of melanin. ${ }^{15}$

At the differentiation stage, the epidermal layers (stratum germinativum, stratum spinosum, stratum granulosum, stratum lucidum, and stratum corneum) are transformed into corneocyte cells. Here at the cellular level, changes occur, such as lamellar body extrusion, loss of the nucleus, and a rise in the keratin content until the SC is formed..$^{16,17}$ The outermost layer of the epidermis is the $\mathrm{SC}$, also known as the nonviable epidermis. The $\mathrm{SC}$ has an approximate thickness of 10-20 $\mu \mathrm{m}$, which can differ from one body part to the other. In a given cross section of skin, it consists of 15-25 stacked, flattened, hexagonal, and cornified cells known as corneocytes or horny cells, attached to a mortar of well arranged intercellular lipids. A brick and mortar model describes this type of arrangement of cells, which serves as a rate controlling barrier in case of transdermal absorption 


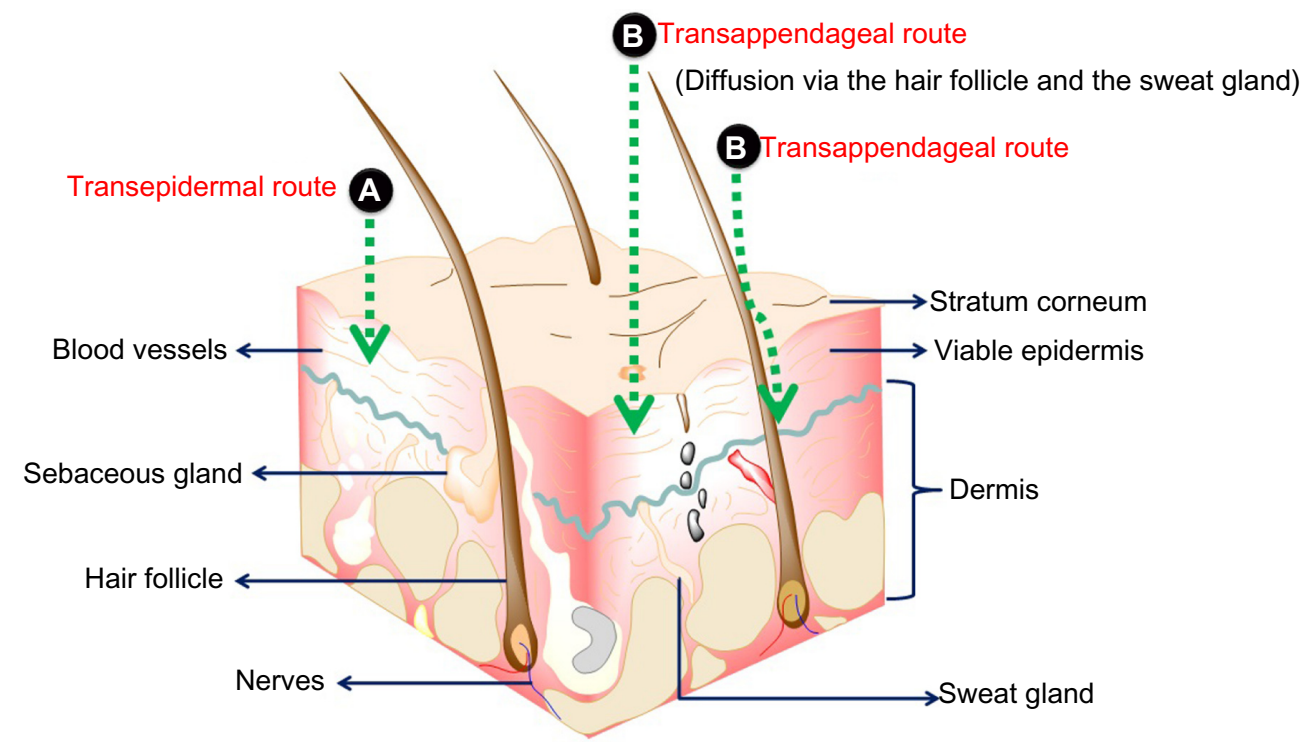

Figure I Skin layers and possible routes of drug delivery to skin layers.

Notes: (A) Transepidermal route, (B) Transappendageal route.

of drugs. Corneocytes are approximately $40 \mu \mathrm{m}$ in diameter and $0.5 \mu \mathrm{m}$ in width and principally comprised of insoluble bundled keratins (approximately 70\%) and lipids ( 20\%) located in the cell covering. The intercellular matrix includes lipids and desmosomes for corneocyte cohesion. ${ }^{16}$

In this area, lipids have noticeable roles in many respects:

- from the skin surface to the base of the SC, lipids constitute the continuous phase

- among biological membranes, the composition of lipids (mainly ceramides, free fatty acids, and cholesterol) is unrivaled, and particularly the absence of phospholipid is remarkable

- despite this shortage of phospholipids, polar bilayerforming lipids and SC lipids present as multilamellar sheets

- principally saturated and long-chain hydrocarbon tails allow a highly arranged and interdigitated configuration. In a lipid matrix, the staggered corneocyte arrangement is proposed to offer an extremely tortuous lipoidal diffusion passage: the membrane becomes 1,000-fold less permeable for water compared to other biological membranes. The intercellular lipid layer is present as a continuous phase for substances of small molecular size, thus it is referred to as the most important pathway for absorption of these kind of substances. ${ }^{18}$ Two to three weeks are required for complete turnover of the SC layer. ${ }^{16}$ It is the main barrier for exchange of substances between the body and environment, because of the composition and structure of the SC. Therefore, it is a tough task for drug delivery through the skin. Furthermore, intracutaneous metabolism, a high drainage rate because of blood and lymph capillaries appear in the dermis, and a peripheral immune system potentiate this anatomical barrier. $^{19}$

\section{Anatomical and physiologic aspects of pilosebaceous units Hair follicles and types}

Pilosebaceous units comprise an integrated organization of hair follicle, hair shaft, and adjacent arrector pili muscles with associated sebaceous glands. Hair follicles are made up of two parts: one is the hair bulb and the other is the hair shaft, which is enveloped in an inner root sheath, then an outer root sheath, and by an outermost acellular basement membrane called glassy membrane. As a keratinized layer, the outer root sheath is present throughout the epidermis, while the inner root sheath ends about halfway up to the follicle. ${ }^{20,21}$ Each hair follicle is coupled with either one or more flask-shaped sebaceous glands, which are outgrowths of epithelial cells. These holocrine glands are connected by ducts to the upper region of the follicle. Regulation of hair growth is governed by cells found near the hair bulb. ${ }^{21}$ Figure 1 shows various skin layers and possible routes of drug delivery to the skin strata.

Human hairs are of two types: terminal and vellus. Macroscopically terminal hairs are pigmented, $>2 \mathrm{~cm}$ long, and $>0.03 \mathrm{~mm}$ thick. Terminal hairs generally contain a medullary cavity, ${ }^{22}$ and present more than $3 \mathrm{~mm}$ depth into subcutaneous tissue. Another type of vellus hair is unpigmented, usually 
short in length $(<2 \mathrm{~cm})$, and thin $(<0.03 \mathrm{~mm})$, and these are typically distributed just $1 \mathrm{~mm}$ into the dermis. Interestingly, some hair follicles can exist in a transitional phase between terminal and vellus forms. The hair follicles in the scalp typically grow as a unit. Each follicular unit is composed of one to four terminal hairs and one to two vellus hairs and encircled by branches from the same arrector pili muscle. ${ }^{23}$ The pilosebaceous unit is a complex and dynamically three-dimensional (3D) structure that controls various activities of a biochemical, immunological, and metabolic nature. ${ }^{24}$

\section{Hair cycle}

Hair follicles have a specific growth cycle that includes alternating multiplication and rest phases. Hair follicles show a growth cycle of three major phases:

- anagen or growth phase - rapid proliferation occurs in a continuous manner to make the inner root sheath, and moves in an upward direction to form the hair shaft

- catagen or involution phase - in this phase, three processes occur: end of mitosis, reabsorption, and cell death of the lower follicle segment

- telogen or resting phase - prior to the hair being shed. ${ }^{25}$ In recent times, the two other stages - exogen (release of telogen fibers from hair follicles) and kenogen (lag time between exogen and development of new anagen fiber) have been expressed as the hair-growth phase. More than $85 \%$ of scalp follicles are found in the anagen phase (period 2-6 years), while approximately $2 \%$ of scalp follicles follow the catagen phase ( 2 weeks), and approximately $10 \%$ are in the telogen phase (2-4 months). ${ }^{26,27}$ The elongation rate of the scalp-hair shaft has been found to be $0.3-0.4 \mathrm{~mm}$ per day. Proliferation and subsequent differentiation of the matrix keratinocytes in bulb sites affect the rate of elongation of hair shafts. The size of the hair bulb determines the thickness of the hair shaft. ${ }^{26}$ If changes occur in the hair cycle, this results in the majority of hair-growth problems.

Androgenetic alopecia is caused by a shortening of the anagen stage, with a clinical consequence of more hair loss, followed by a conversion of terminal to vellus hair follicles, termed miniaturization. However, hypertrichosis and hirsutism conditions can show a prolonged anagen phase with conversion of vellus hair follicles into terminal. ${ }^{28}$ The endocrine system, and particularly the pineal gland, modulates hair growth upon seasonal changes, because of a reciprocal relationship between circulating prolactin levels and melatonin concentrations, elevated during summer and lessened in winter.

The synthesis and release of sebum are additional key functions of pilosebaceous units, comprised of short-chain fatty acids with fungistatic and bacteriostatic properties. The total disintegration of glandular cells of pilosebaceous units secretes sebum and is discharged through ducts into the upper third of the follicular canal. ${ }^{29}$ In this region of the follicle, sebum provides an environment of neutral and nonpolar lipids. The human sebum contains 57\% triglycerides, 26\% wax esters, and approximately $2 \%$ squalene. Sex hormones and age affect glandular activity for secretion of sebum. Secretion is lacking in infants, accelerated at puberty, and decreased in elderly persons. Interestingly, the density or size of follicles is not affected by the sebum-production rate, ${ }^{29}$ but there is some contention related to the effect of temperature on the secretion of sebum. It has been found that secretion is steady irrespective of season, ${ }^{30}$ but other evidence suggests that sebum output is augmented in hot conditions. ${ }^{31}$ Figure 2 presents the factors affecting sebum production in humans.

\section{Types of hair follicles}

Generally, hair follicles are of two types: terminal follicles which are androgen-free hair (eyebrows, lashes) and vellus follicles which are hormone-dependent hair on the scalp, beard, chest, axillae, and pubic region. They are comprised of $>2 \mathrm{~cm}$ long terminal hair shafts with a thickness of $>60 \mathrm{~mm}$, are pigmented, and contain medullae. ${ }^{32,33}$ Most scalp hairs are not medullated, and medullae are only present in prominent terminal hair fibers. ${ }^{34}$ Terminal hair generally extends more than $3 \mathrm{~mm}$ into the hypodermis. The remaining body of adults is covered with vellus hair, short $(<2 \mathrm{~cm})$ and thin ( $<30 \mathrm{~mm}$ diameter). These hairs are usually unpigmented and extend just $1 \mathrm{~mm}$ into the dermis part. Some hair follicles can exist in a transitional phase between terminal and vellus forms. ${ }^{25,26,32,35}$ Palms of the hand, soles of the feet, lips, and parts of the external genitalia are only the skin regions devoid of hair follicles. ${ }^{34,36}$ The hair follicles in the scalp region are characteristically organized in the follicular unit, comprised of one to four terminal hairs and one to two vellus hairs, and encircled by branches of arrector pili muscle. ${ }^{25,35}$

\section{Numeric occurrence and size of hair follicles}

In the past, follicular penetration was ignored, because it was assumed that hair follicles covered $<0.1 \%$ of total skin area. However, recent studies have concluded that the above assumption is acceptable for the inner side of the forearm, which is generally employed for skin-permeation studies as an experimental region. However, hair follicles of different body regions show variations in number of hair follicles, follicular orifice size, diameter of hair shafts, and volume 


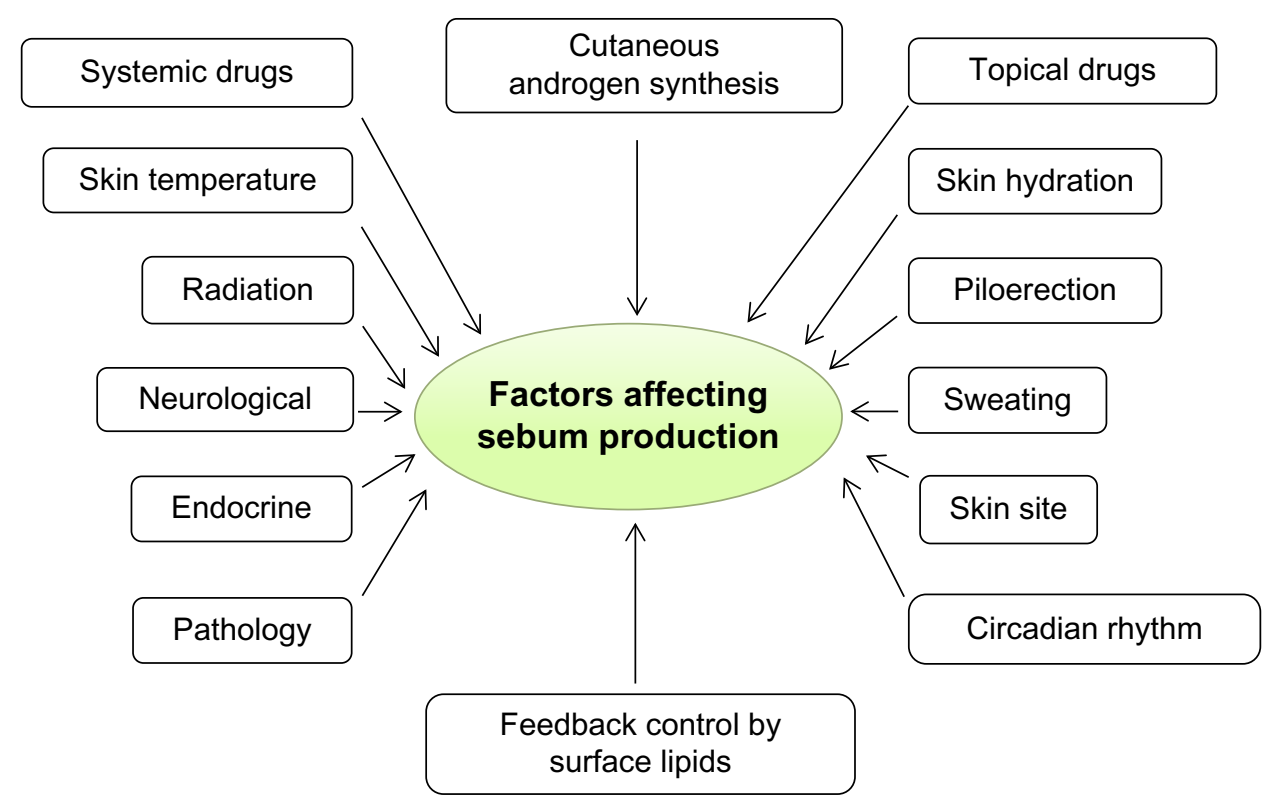

Figure 2 Factors affecting sebum production in humans.

and surface of infundibula. For follicular penetration studies, knowledge of hair-follicle density and size are a necessary requirement.

Hair shafts show comparatively minute differences in diameter (16-42 $\mathrm{mm}$ ). Maximum shaft diameters are observed in the sural $(42 \mathrm{~mm})$ and thigh $(29 \mathrm{~mm})$ regions, with the narrowest on the forehead $(16 \mathrm{~mm}) \cdot{ }^{37}$ The maximum hair-follicle density is found on the forehead, ie, 292 follicles $/ \mathrm{cm}^{2}$. The maximum follicular infundibula volume, which is represented as a potential follicular reservoir for dermally enforced compounds, is found on the forehead, ie, $0.19 \mathrm{~mm}^{3} / \mathrm{cm}^{2}$, as well as in the sural area, ie, $0.18 \mathrm{~mm}^{3} / \mathrm{cm}^{2}$. In comparison to the reservoir of the $\mathrm{SC}$, all follicles are open for the penetration process in the follicular reservoir on the forehead. ${ }^{37}$ For the scalp and face, the combined areas of follicular openings can be more than $10 \%$ of the total skin area. ${ }^{38}$

\section{Transfollicular drug delivery Hair follicles and potential drug-targeting sites}

The medulla, cortex with melanosomes, and the cuticula constitute the hair shaft, and have flat and cornified cells (roof-tile arrangement). ${ }^{35}$ The hair shaft can be divided into:

- the infundibulum, present between the skin surface and the duct-opening point of the sebaceous gland to the hair canal

- the isthmus, found between the bulge area and the ductopening point of the sebaceous gland
- the suprabulbar zone, where differentiation of different layers of anagen follicles start and are identified very easily at this level

- the hair bulb, with the dermal papillae linked to the blood vessels.

The outer root sheath is a stratified epithelium that surrounds the hair follicle continuously with the epidermis. ${ }^{35}$ The superficial portion of the hair-follicle infundibulum (acroinfundibulum) is lined by the epidermis, including a considerably developed SC and a stratum granulosum layer. The lower region of the infundibulum, referred to as the infrainfundibulum, may get an uninterrupted loss of epidermal differentiation toward the isthmus, and acts as a most important entry portal for applied contents..$^{39,40}$

The sebaceous gland serves as a potential therapeutic target site, and is engaged in acne etiology and androgenic alopecia. $5 \alpha$-Reductase is expressed in androgenic alopecia, particularly in regions of the face and scalp, and changes testosterone to the more potent metabolite $5 \alpha$-dihydrotestosterone. ${ }^{41}$ Considerable efforts have been reported to show the maximum accumulation of different bimolecular substances in androgen-dependent glands. Additionally, a wide capillary bed coupled with the upper dermal vasculature provides the upper follicle and sebaceous glands with blood, producing the opportunity of systemic drug delivery. ${ }^{42}$ The bulge region is situated just below the sebaceous glands, which is responsible for follicle reconstitution and could be another attractive targeting site. It is comprised of stem cells of high proliferative capacity. These 
cellular areas are the specific target area for gene delivery to help in long-term correction of genes in cases of genetic skin disorders/congenital hair disorders. The hair-bulb region with hair-matrix cells regulates hair growth and pigmentation. ${ }^{32}$

Teichmann et $\mathrm{al}^{43}$ developed a method to differentiate transepidermal and transfollicular permeation. They utilized a varnish-wax mixture to block follicles selectively. The varnish-wax mixture was used for the determination of chemical and physical ultraviolet filters and curcumin penetration into follicles, in addition to in vivo follicular penetration of caffeine, which was utilized in a shampoo formulation. Differential stripping allows determination of the amount of a topically applied substance that penetrates into the hair follicles. The technique combines the tape-stripping procedure (removing the SC layer by layer), followed by biopsies of cyanoacrylate skin surface (taking out the components of the follicular infundibulum, the "follicular cast" consisting of a mixture of keratinized material, cell detritus, lipids and, bacteria). ${ }^{44-46}$

\section{Barriers to follicular drug delivery}

Although pilosebaceous units may be acceptable as either potential target sites or shunts for delivery of various drugs drug, arrival into these skin structures can be difficult, due to architectural and physicochemical hindrance. ${ }^{5}$ Table 1 shows a list of these possible barriers, with corresponding resolving strategies..$^{7,12,47-50}$ The size selectivity of the follicular openings can represent a potential barrier for particulate-delivery systems.

In human facial skin, it is reported that fluorescent polystyrene microbeads ( $7 \mu \mathrm{m}$ diameter) show maximum follicular deposition. Beads of larger size retain more on the surface of the skin, while smaller beads cross the superficial layers of the SC. ${ }^{47}$ Very similar results were found with dansyl chloride-labeled microbeads. Various studies of polymeric microspheres reported a diameter of $5 \mu \mathrm{m}^{12}$ or $1.5 \mu \mathrm{m}^{47}$ as

Table I Potential barriers and resolving schemes combined with drug delivery into pilosebaceous glands

\begin{tabular}{|c|c|c|c|}
\hline $\begin{array}{l}\text { Potential } \\
\text { barriers }\end{array}$ & Resolving scheme & Bioactive & References \\
\hline $\begin{array}{l}\text { Size } \\
\text { selectivity }\end{array}$ & $\begin{array}{l}\text { Optimize microparticle } \\
\text { diameter } \\
\qquad \begin{array}{l}.5-7 \mu \mathrm{m} \\
2.2-40 \mathrm{~nm}\end{array}\end{array}$ & - & $12,47-49$ \\
\hline \multirow[t]{2}{*}{ Sebum } & $\begin{array}{l}\text { Utilize a lipophilic } \\
\text { penetrant }\end{array}$ & Curcumin & 7 \\
\hline & $\begin{array}{l}\text { Utilize a vehicle miscible } \\
\text { with sebum }\end{array}$ & $\begin{array}{l}\text { Propylene } \\
\text { glycol }\end{array}$ & 50 \\
\hline \multirow[t]{2}{*}{ Hair cycle } & Apply penetrant during anagen & DNA & 51 \\
\hline & & Curcumin & 7 \\
\hline
\end{tabular}

optimal for effective penetration. However, there may be other considerable size-selective methods functioning at the micromillimeter scale. In current studies with porcine skin, it was decided that polystyrene particles of $20 \mathrm{~nm}$ diameter presented much higher follicular deposition than particles of $200 \mathrm{~nm}$ diameter. ${ }^{48}$ In addition, minoxidil-encapsulated microparticles of $40 \mathrm{~nm}$ diameter were found to be superior to particles of $130 \mathrm{~nm}$ diameter in the context of facilitating transdermal drug penetration through the skin of hairy guinea pigs. ${ }^{49}$ Table 2 presents various microparticulate systems intended for follicular drug delivery. ${ }^{12,38,47-49,52,53}$

The sebum may hinder upward transportation of substances, especially of hydrophilic drugs. An in vitro study with rodent skin revealed that release of sebum from the sebaceous gland was induced by a mild heating process, and thus sebum filled the follicular space and also obstructed the follicular penetration path of various drugs of a hydrophilic nature. ${ }^{54}$ In contrast, for the follicular uptake of a few lipophilic molecules, the presence of sebum may be a prerequisite. In this context, the penetration of moderately lipophilic substances, such as curcumin $\left(\log \mathrm{K}_{\mathrm{o} / \mathrm{w}}=3.3\right)$ via human skin was followed by a combination of stripping, staining, and laser-scanning microscopy (LSM). ${ }^{7}$ The nature of the follicles was found to be either active or inactive. Active follicles were those engaged in sebum formation and/or hair-growth processes, while inactive follicles did not show hair growth or sebum production. It was observed that the curcumin penetrated active follicles but not the inactive ones, due to a phenomenon performed by the hair-follicle shaft referred to as "proposed pumping". In the case of sebum, it has been suggested that formulation with a suitable wetting agent could ensure that the vehicle shows good contact with the sebum throughout the vent of the duct. ${ }^{50}$ However, the role of sebum in drug delivery is still poorly understood. Before extrapolating the data from animal to

Table 2 Microparticulate systems intended for follicular drug delivery

\begin{tabular}{lll}
\hline Skin model(s) & $\begin{array}{l}\text { Microparticulate fabrication } \\
\text { with size range in nm }\end{array}$ & Reference \\
\hline Human and rhino mouse & PLGA with adapalene; 5,000 & I2 \\
Human & Titanium dioxide; I7 Polystyrene; 38,47 \\
& I,000-24,000 and 750-6,000 & \\
Pig & Polystyrene, 20-200 & 48 \\
Hairy guinea pig & PCL block-PEG with minoxidil; & 49 \\
& $40-130$ & \\
Hairless rat & Porous nylon with methylene & 52 \\
& blue; 5,000 & \\
Pig; regrown human & Solid-lipid nanoparticles with & 53 \\
epidermis & Nile red and silver; I50-500 & \\
\hline
\end{tabular}

Abbreviations: PEG, polyethylene glycol; PLGA, poly(lactic-co-glycolic acid). 
human studies, differences in sebum chemistry among the several species should be accepted. The preparation of artificial human sebum ${ }^{55,56}$ and use of differential scanning calorimetry are required for explanation of artificial sebum-drug interaction characteristics, ${ }^{57,58}$ and may show the way forward. Pilosebaceous drug delivery is also influenced by the hair-growth cycle. It has been suggested that the hair-growth cycle influences the delivery of liposomeencapsulated fluorescent molecules. ${ }^{59}$

Optimization of DNA transfection into human hair follicular cells was performed during the start of the anagen phase. ${ }^{51}$ The deposition of curcumin was also limited in human skin follicles during the anagen phase. ${ }^{7}$ Although the mechanism is not well defined, identifying the particular cycle of hair-growth phase appears to be essential for standardizing experimental circumstances (Table 1).

\section{Physicochemical characteristics for transfollicular delivery}

The simplest method selects a therapeutic from various pharmacological categories that has appropriate physicochemical characteristics to penetrate into the pilosebaceous unit. A useful method is a simple equation for steady-state flux that considers factors related to the penetration rate of drug molecules via the horny layer. ${ }^{60}$ Permeation into the pilosebaceous unit via hair follicles, focusing on the therapeutic to be targeted, showed that various features of the moiety determine its penetration. Generally, controlling properties for penetration can be changed for short-term or finite-dose (depleting) conditions. ${ }^{60}$ The cumulative amount of penetrants, ( $m$ below) passing per unit area via the SC can be calculated using the formula:

$$
\frac{d_{m}}{d_{t}}=\frac{D C_{0} K}{h}
$$

where $C_{0}$ is the constant concentration of the drug in the donor system, $K$ is the partition coefficient of penetrants, $D$ is the diffusion coefficient, and $h$ is the thickness of membrane.

From Equation 1, we derive the ideal characteristic of a moiety penetrating into the pilosebaceous unit. These are:

- low molecular weight, generally not more than $600 \mathrm{Da}$, when Dalton count tends to be high

- sufficiently soluble in nonaqueous and aqueous media, so the membrane concentration gradient (the driving force for diffusion) may be high ( $C$ is large)

- saturated solutions (or suspensions having the same maximum thermodynamic activity) encourage maximum flux in equilibrium systems; high but balanced (optimal)
$K$ (too large may suppress clearance by live tissues); low melting point, correlating with good solubility as predicted by ideal solubility theory

- potential for binding with skin components and metabolism in skin should not be ignored; binding metabolism may reduce the amount of drug moiety being delivered in the follicular site. ${ }^{61}$

\section{Potential candidates for transfollicular drug delivery}

Hair follicles are seen as a promising target for transcutaneous drug delivery, ${ }^{6,10,40}$ especially for gene therapy and vaccination. ${ }^{59}$ Table 3 lists suitable candidates for transfollicular drug delivery. ${ }^{62-77}$

\section{Schemes for enhancement of follicular delivery of therapeutics}

Efforts are continuously under way to enhance the extent of follicular delivery with advances in nanotechnology-based modulation at both the macro- and micro-levels. Adopted schemes have incorporated the application of optimized vehicles, microspheres, liposomes, and lipoplexes, as well as iontophoresis. The literature referring to each of these schemes is sequentially elaborated in the following sections.

\section{Optimization of vehicle}

The vehicles used in the formulation can highly influence the extent of follicular drug delivery. For effective pilosebaceous drug delivery, one of the suggested strategies is that a volatile organic solvent like ethanol is used to dissolve and remove sebum from the follicular duct. ${ }^{50}$ The percutaneous absorption

Table 3 Suitable candidates for transfollicular drug delivery

\begin{tabular}{ll}
\hline Drug candidate & Reference \\
\hline Tacrolimus & 62 \\
Dithranol & 63 \\
5-Aminolevulinic acid & 64 \\
Caffeine & 65 \\
Cyclosporine & 66 \\
Triamcinolone acetonide & 67 \\
Enoxacin & 68 \\
Trihexyphenidyl HCl & 69 \\
Corticosteroid & 70 \\
Low-molecular-weight heparin & 71 \\
Unfractionated heparin & 71 \\
Progesterone & 72 \\
Paromomycin & 73 \\
PDNA & 74 \\
Adriamycin & 75 \\
Estradiol & 76 \\
Levonorgestrel & 77 \\
\hline
\end{tabular}

Abbreviation: pDNA, plasmid DNA. 
of pyridostigmine bromide with excised rat skin was found to be maximum with the application of ether, ethanol, dimethyl sulfoxide, or propylene glycol. ${ }^{78}$ In contrast, the addition of terpene, nerol, or ozone in the preparation decreased transfollicular penetration, due to hindrance in transport via the SC. In experiments applying a hamster-ear model, it was found that salicylic acid accumulation in the follicles attained maximum levels when lipophilic vehicles rather than hydrophilic vehicles were used. ${ }^{58}$

In an in vitro experiment with human scalp skin, Grams et al found that application of different combinations of propylene glycol-surfactant enhanced accumulation of lipophilic dyes in the follicle, while the application of $30 \%$ ethanolic solution was optimal for less lipophilic dyes. ${ }^{9}$ In mouse skin, Dokka et al examined modified oligonucleotidedeposition kinetics. They reported follicular accumulation of an oligomer by using a saline solution, while a lipophilic cream delivered the nucleotide into the dermis but not into the follicle. ${ }^{79}$

Several emulsion-based systems as follicle-targeting vehicles have been examined. Topical application of plasmid DNA-loaded water-in-oil nanoemulsions led to enhanced DNA transfection into follicular keratinocytes of mouse skin. ${ }^{80}$ Other studies have been performed for the comparison of different water-soluble penetrants with respect to transdermal penetration via rat skins showing density differences in follicles. ${ }^{81}$ The researchers predicted that encapsulation of compounds within oil-nanoemulsion droplets would show increased transportation of water-soluble substances via the follicular route. Moreover, the hydrophilic-lipophilic balance of the surfactant blend used in the preparation was found to affect the rate of follicular transport of inulin (model penetrant). This study showed that greater transfollicular transport of inulin was the result of lower hydrophilic-lipophilic balance values of the surfactant. Mechanistically, it was suggested that the administration of solubilized penetrant through the follicular route was potentiated by the sebummiscible external oil phase. It was also found that salicylic acid deposition in the follicular area could be increased in a water-in-oil system by providing more oil-phase volume. ${ }^{58}$

\section{Applications of microparticulate systems}

Numerous efforts have been directed toward the fabrication of microparticulate follicle-targeting strategies. Some of these research experiments have been exercised employing several animal models. For example, one team prepared different topical formulations composed of poly(D,L-lactic- $c o$-glycolic acid) microspheres. ${ }^{12}$ Adapalene-loaded microspheres (5 $\mu \mathrm{m}$ diameter) showed antiacne properties. Evaluations with an in vivo rhino/mouse model showed a high comedolytic property of the system. Recently, Mordon et al ${ }^{52}$ explored the fate of dye-loaded porous nylon microspheres ( $5 \mu$ m diameter) when these were employed on the skin of hairless rats. Interestingly, after 26 hours' treatment, dye was extensively distributed inside the follicular site and sebaceous glands, which penetrated up to a depth of approximately $400 \mu \mathrm{m}$ below the skin surface. In another investigation on pork skin, fluorescent dye loaded polystyrene nanoparticles showed prominent penetration. ${ }^{48}$ To visualize particle penetration through the tissues, confocal LSM (CLSM) was utilized. Surface imaging showed that the nanoparticles were primarily collected in the openings of certain follicles in a time-dependent manner, while in porcine skin, engineered "solid-lipid particles" showed increased delivery of fluorescent molecules preferentially to the hair follicles. ${ }^{53}$

Human skin is considered the most relevant study tool compared to other models, due to variation in the morphological and physiological characteristics of species. In this context, poly(D,L-lactic-co-glycolic acid) microspheres containing adapalene were applied topically, and showed a deposition of adapalene in human skin, especially in follicular regions. ${ }^{12}$ These microsphere formulations presented superior efficacy compared to simple adapalene aqueous gels. Lademann et al analyzed the deposition process of coated microparticles with titanium dioxide, commonly used in commercial sunscreen products. ${ }^{38}$ Mostly, particles were retained on the surface of skin or administered by penetration into the superficial layers of the SC. However, less than $1 \%$ of the microparticles were collected in the upper regions of the hair follicles. Toll et al used polystyrene microspheres at a size of $0.75-6.0 \mu \mathrm{m}$ onto freshly excised human skin samples. ${ }^{47}$ These human skin samples were subjected to shock-freezing and slicing into $5 \mu \mathrm{m}$ sections, to visualize microparticle deposition using fluorescence microscopy. It was observed that the microspheres penetrated hair follicles up to $1,000 \mu \mathrm{m}$ beneath the skin surface. Lademann et al suggested that a "pumping" mechanism in the hair shaft was

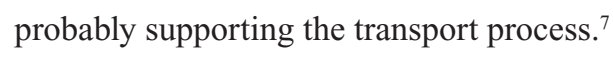

\section{Use of liposomes}

Liposome has been found to be a potential carrier for delivery of various therapeutic molecules into targeting sites. The follicular region is the most approachable site for drug delivery via liposomes. ${ }^{82,83}$ Over a decade ago, Balsari et al reported that liposomes modified with monoclonal antibodies were used as a protective measure for alopecia induced by doxorubicin in rats. ${ }^{84} \mathrm{Li}$ and Hoffman found that calcein-, melanin-, and DNA-loaded liposomes improved 
the accumulation of each penetrant inside the follicles of histocultured mouse skin compared to aqueous control solutions. ${ }^{85}$ On the other hand, experiments have also been carried out for exploring the topical potential of liposomes (nonionic) for both hydrophobic (eg, cyclosporine A) and hydrophilic bioactives (eg, $\alpha$-IFN). ${ }^{86}$ There was significant accumulation of both drugs in follicles in vivo (hamster-ear model). Interestingly, ionic liposomes were found to be ineffective for pilosebaceous drug delivery. In vivo studies in a mouse model with nonionic liposomes showed that they promoted delivery of minoxidil as well as plasmid DNA to the follicles. ${ }^{87}$ Recently, fluorescence-imaging techniques were applied for studying the deposition of the anticancer drug adriamycin in the follicular region of a hairless rat model. ${ }^{75}$ It was revealed that accumulation of adriamycin in the follicular site was improved considerably, due to liposomal encapsulation, depending upon the composition of liposome. Similarly, Verma et al showed effective induction of hair growth in Dundee experimental bald rats with cyclosporine encapsulated in liposomal formulations. ${ }^{88}$

\section{Applications of topical lipoplex}

Lipoplexes are a potential drug-delivery approach that employs DNA-cationic lipid complexes designed to facilitate transfection. Cationic liposomes are blended with either plasmid DNA or oligonucleotides, resulting in formation of complexes spontaneously. It has been expressed that the nucleotides contain a negative charge, which can bind to cationic lipids with electrostatic bonding. ${ }^{89-91}$ In vitro studies with follicles of human hair demonstrated that intrafollicular delivery of oligonucleotides was improved by lipoplex-based formulations. ${ }^{92}$ Approximately $0.5 \%$ of the employed dose was delivered within 24 hours after topical application to hair bulbs and the deeper skin layers. ${ }^{92}$ Further, in an in vivo experiment on both mouse skin and human xenograft, the transfection potential of hair follicle's progenitor cell was established. $^{51}$

\section{lontophoresis}

Several studies have shown that hair follicles act as channels rather than depots for the iontophoretic flux of different molecules. ${ }^{93}$ Iontophoresis may be especially beneficial for delivery of ionic, polar and its compounds of high molecular weight at systemic sites, which usually have slow or negligible absorption in passive mode..$^{94-96}$

\section{Microneedling}

Microneedling is a physical method that induces modification in the SC mechanically and produces micron-sized channels or pores in the skin. This characteristic of the microneedling technique provides delivery of various molecules or therapeutic substances, including proteins, which would usually not penetrate via unbroken skin. ${ }^{97-99}$ These induced microchannels spontaneously shut after some time (approximately 10 minutes), and the epidermal barrier stays intact. ${ }^{100}$ This method is advantageous over other therapies due to its mechanism of altering the upper skin layers utilizing fractional laser. Earlier investigations have demonstrated that microneedling enhances the absorption of different compounds through skin absorption. ${ }^{101-104}$ Microneedling potentiates the delivery of therapeutics more efficiently and penetrates deeper skin. In other research, triamcinolone acetonide was introduced with microneedling into alopecia areata patients $(n=2)$, and increased drug absorption with its known immunomodulatory activity. ${ }^{104}$ One more benefit of this combination could be that the microneedling technique stimulates collagen and hence may counter the chance of atrophy induced by triamcinolone. Microneedling has also been applied to promote the penetration of minoxidil. This approach induces hair stem cells and growth factors in alopecia androgenetica. ${ }^{103}$ Microneedling may also be helpful to promote the penetration of aminolevulinic acid (ALA) or methyl aminolevulinate in photodynamic therapy (PDT) into the skin. ${ }^{101,105}$ Clementoni et al treated 21 persons with photoaging by applying PDT with light of $630 \mathrm{~nm}$. This "pretreatment" prior to application of ALA seemed to be well tolerated, and permitted better absorption and possibly deeper permeation of ALA following the set incubation time. ${ }^{101}$ Torezan et al also applied microneedling-aided PDT to improve the penetration of methyl aminolevulinate into the upper layer of skin of patients with solar keratosis. ${ }^{105}$

\section{Nanocarrier-based approaches Niosomes}

Tabbakhian et al reported that colloidal vesicular systems like niosomes (nonionic surfactant-based vesicles) and liposomes were superior to conventional formulations (eg, aqueous alcoholic solutions) in transfollicular targeting of drugs. ${ }^{106}$ Niosomes showed blending of skin lipid(s) and phospholipids, which resulted in improvement of drug penetration into the skin. Membrane characteristics of the SC changed with niosomes as they fused with the upper layer of the skin, and led to improved drug permeation. It was proposed that niosomes are a potential candidate for controlled and targeted drug delivery. ${ }^{107}$ Niosomes enhanced the permeation of numerous chemicals and drugs through the SC. Minoxidil (2\%)-loaded niosomes expressed more dominant hair growth compared to a conventional dosage form. Niosomes also 
participated in the improved permeation of DNA, proteins, and peptides. For drugs and chemicals, Span and Tween are commonly used materials for the synthesis of niosomes. Polyoxyethylene ether and diacylglycerides are applied for the encapsulation of protein and DNA. Ciotti and Weiner demonstrated human IL-1 expression level of pDNA by application of various formulations. pDNA expression from niosomes was significantly superior to the phosphatidylcholine-based liposomes and control formulation tested. ${ }^{87}$

\section{Nanoparticulate delivery into hair follicles}

Nanoparticulate systems improve the skin absorption and bioavailability of drugs/chemicals, as well as permit drug targeting into the skin and/or its substructures. ${ }^{108}$ Application of small particulates ensures close contact with the SC. ${ }^{109}$ Nanoparticles also allow close contact with superficial junctions of the SC and the furrows present among the corneocytes, which provide effective permeation of active principle in superficial layers of skin. Subsequently, evaporation of the aqueous phase from the nanoparticulate system applied on the skin surface results in skin occlusion. The SC becomes more hydrated with decreased corneocyte packing, as well as extended intercorneocyte gaps, subsequently improving the transport of the drug. Topically applied nanoparticles tend to diffuse and accumulate in the hair follicle; these characteristics assign nanoparticles penetration and depot-forming capacities. ${ }^{110,111}$ They are frequently employed for medical and cosmetic purposes. ${ }^{108,112}$ Nanoparticles of $\sim 300 \mathrm{~nm}$ in size penetrate more deeply into the pilosebaceous unit than nonparticle contents. These nanoparticles are also stored for a longer time period in the follicular region than nonparticle materials. Toll et al analyzed hair follicles of excised human skin with penetration of particles of sizes 0.75 and $6.0 \mu \mathrm{m} .{ }^{47}$ It was observed that $0.75 \mu \mathrm{m}$ particles permeated better and more deeply into the pilosebaceous unit than larger particles. The cause for the effective nanoparticle penetration appears to be a pumping phenomenon developed by the rigid hair shafts. The movement of hair serves as a geared pump; because cuticular layers have a zigzag structure along the hair shaft. ${ }^{109}$ Movement of hairs pushed the particles into the hair follicles, which are similar in size to hair cuticles. Live tissues continuously performed these movements. ${ }^{113}$ Nanoparticles applied onto the skin surface can accumulate in the follicular opening and penetrate along the follicular duct. It is advantageous to treat various dermatological problems with regard to appendages. Moreover, the nanocarrier system can deliver the active drug moiety not only into the skin more deeply but also into the systemic circulation for therapeutic aims. This strategy is successfully applied in numerous nanoparticulate formulations, such as polymeric, metallic, and lipid nanoparticles.

\section{Polymeric nanoparticles}

Various nanoparticles have been explored for potential application in absorption via the follicular route. Among these, the polymeric nanoparticle is an efficient tool for follicular drug delivery. Polymeric substances, such as polyvinyl alcohol, polystyrene, polylactic acid, polyethyleneimine, polyglycolic acid, poly(lactic-co-glycolic) acid, and cellulose, are applied for the formation of polymeric nanoparticles to deliver drugs/chemicals into the follicles. Polystyrene-based nanosystems are the first nanoparticle system approached for follicular drug delivery. Alvarez-Román et al applied carboxylate-altered polystyrene nanoparticles of 20 and $200 \mathrm{~nm}$ diameter to analysis of skin-penetration and -distribution patterns. ${ }^{48}$

\section{Lipid nanoparticles}

Sebum is present in large amounts inside the follicular ducts. Due to the lipophilic nature of sebum, components can easily interact with lipid-based nanocarriers. Based on this fact, the nanoparticles of lipid materials may be beneficial for sebum interaction and subsequent aggregation in the pilosebaceous unit. Solid-lipid nanoparticles and nanostructured lipid carriers are new generations of lipid nanoparticles formulated from solid lipids. Solid-lipid nanoparticles are made up of pure solid lipids, while nanostructured lipid carriers are manufactured by a solid matrix that encloses liquid-lipid nanocompartments. ${ }^{14,115}$

\section{Newer techniques for follicular delivery}

To date, a major problem in assessing drug delivery via the transfollicular route has been the lack of a quantitative model system that is free of follicles but maintains the properties (structural, biochemical, and barrier) of normal skin. Earlier models have proved extremely useful for studying follicular penetration, such as in the Syrian hamster ear, the fuzzy rat, the macaque monkey, and the regrown scar-tissue system. ${ }^{6}$ Importantly, in recent years, two novel quantitative systems have emerged, and these are reported in the following sections. Furthermore, development in newer technologies has simplified ongoing advances in visual imaging techniques, and some developments within this context are also reviewed. 


\section{The skin-sandwich system}

Recently devised and validated, the in vitro skin-sandwich or composite system can be used to quantitatively deconvolute the role of hair follicles to total drug penetration. ${ }^{8,116,117} \mathrm{In}$ this technique, overlaying of an extra SC layer onto a human epidermal membrane is employed in the arrangement of a sandwich or composite dual membrane. It is essential that both components of this system are from the same skin donor. Interestingly, the shunt pathway via both components of the membrane is obstructed. The theory behind the approach is less complicated. Through a solid homogenous membrane passive at a steady state, drug flux is indirectly proportional to the path length traveled by the permeant. Human skin contains primary barrier penetrants within the SC; therefore, flux via the sandwich system should be just half that through the single epidermis if the shunts provide a lot less contribution to the penetration mechanism. On the other hand, if sandwich flux is considerably less than half the flux of the epidermis, then that would prove that the role of the shunt route is notable. Similarly, estimation of the shunt contribution is also possible by measurement of lag times, since these are directly proportional to the square of the path length.

Skin sandwich system is based on few reasonable assumptions. First, it is assumed that the shunts express hair follicles and that the opening of sweat ducts with smaller measurements shows a smaller contribution to the drugabsorption process. Second, the nucleated epidermis exhibits minute resistance to permeation, and is not considered for the sake of simplicity. Moreover, for highly lipophilic drugs, the system cannot be used, because the penetration of such compounds means the $\mathrm{SC}$ will no longer be the main barrier. Finally, the theory assumes that new pores are not produced during the permeation mechanism. In spite of these limitations, the skin-sandwich system in drug-delivery research acts as a very powerful tool. This was highlighted by Barry with the help of a theoretical analysis, who considered that in practice what occurs is the two membranes do not adhere strongly together. ${ }^{117}$ The possible reason would be the presence of few aqueous channels lying laterally within the skin layers. However, application of a Monte Carlo simulation showed that even assuming incomplete adherence, the distance traveled by a molecule during this lateral diffusion was very long in comparison to SC thickness and nucleated epidermis constituting the bottom layer. Therefore, the results can still be safely interpreted on the basis of ideal contact behavior, even though adherence in the sandwich is imperfect.
In various experimental settings, the skin-sandwich system has already seen use. ${ }^{116}$ Involvement of the follicles in the penetration of estradiol via the transepidermal route was investigated using ultradeformable liposomes. It was observed that the follicular route played a very minor role in the delivery of estradiol from these liposomes. Afterward, for the comparison of skin permeation of mannitol with estradiol under passive circumstances, the sandwich technique was employed. ${ }^{8}$ Mannitol is considered a model permeant of hydrophilic nature, while estradiol behaves as a model lipophilic drug. It was found that during the initial 8 hours of drug penetration, follicles mediated the transport of mannitol completely, while estradiol exhibited entirely nonfollicular penetration. When mannitol flux was compiled over a longer timescale, a more complex picture emerged. Interestingly, estradiol encapsulated in liposomes did not affect the nonfollicular route preference of drug. Overall, the skin-sandwich system obviously behaves as an effective novel tool that has yet to be completely employed in mechanistic research of skin transport.

\section{The sebum-discharge approach}

This in vitro methodology relies on the fact that discharge and filling of sebum to the follicle shaft from sebaceous glands is induced by either the treatment with mild heating $\left(42^{\circ} \mathrm{C}\right)$ or by application of low-intensity ultrasound ${ }^{54}$ Skins of Wistar rats or guinea pigs are used for the estimation of the sebum-discharge effect. It has been shown that deposition of lipid in the shafts blocked this route for the transport of hydrophilic compounds. In male Wistar rat skin, it was found that sucrose and mannitol were absorbed virtually via the follicular route. It is yet to be demonstrated whether this mechanism improves in human skin. ${ }^{49}$

\section{Advanced optical imaging systems}

As mentioned earlier, CLSM has become a well-established noninvasive imaging method with high resolution for skin, as well as other biological tissues. ${ }^{48,118}$ The main benefits of this methodology include its good time-resolution nature, in vivo application capacity, and visualization ability at multiple depths that are parallel to the surface of samples without any required mechanical sectioning. Grams et al extended CLSM cross-sectional imaging in unfixed, fresh human skin with the use of online drug-diffusion visualization., ${ }^{9119}$ In vitro study in human scalp skin with this variant CSLM approach showed quick transport of lipophilic labels through follicles from an employed aqueous solution. ${ }^{9}$ The combined effort 
of confocal Raman spectroscopy and confocal microscopy used is another promising approach for analyzing follicular drug delivery. ${ }^{120}$ Optical coherence tomography is a further new methodology, and has been used in combination with LSM for imaging of follicular pores. ${ }^{37}$ This technology is currently applied to distinguish open-hair follicles from follicles attached with corneocytes.

\section{Immunization through transfollicular route}

For transdermal delivery, the presence of the SC barrier is the main hurdle for the penetration of therapeutics into deeper sites of the skin. Transcutaneous immunization is a needle-free approach for vaccination through the skin. ${ }^{121}$ Unmasked vaccine antigens and conventional vaccine preparation cannot overcome the barrier function of human skin $\mathrm{SC}$ to a degree that would permit the significant delivery of a considerable amount of antigen. However, needle-free vaccination is preferably selected to avoid the probability of contamination, which usually occurs with syringes due to the probability of spreading communicable diseases by sharing needles. Transcutaneous immunization combines the benefits of other routes applied for mucosal vaccination employing needle-free techniques. This method is potentially free of risk, convenient, and economical. Generally, immunization via the mucosal route shows superiority to conventional vaccination via intramuscular or subcutaneous injection. Transfollicular delivery is being demonstrated as an alternative pathway for vaccination. ${ }^{122-125}$ Some experiments have shown that vaccination via the transfollicular route may support a biased response by $\mathrm{CD} 8^{+}$, which would be a plausible mode of action of vaccines against endogenous pathogens or virus contamination. ${ }^{123}$ In transfollicular vaccination, antigen-loaded carriers would be trafficked throughout the hair follicles to arrive at the site of abundant perifollicular Langerhans cells, which may act as antigenpresenting cells. ${ }^{126}$

Appendages of skin and hair follicles contain several parasitic microbes in large numbers. The lower part of hair follicles has no SC, so tight junctions may participate as compensatory mechanisms when a physical barrier is not present. ${ }^{127}$ Tight junctions in contact with the immunological barrier expressed by other epithelium tissue, including interfollicular epidermis, acts as a barrier. ${ }^{128}$ The number and activation state of perifollicular Langerhans cells are both linked to hair cycling in a dynamic pattern. ${ }^{129}$ Also, it has been demonstrated that the reaction toward allergens applied topically is less marked throughout the anagen (ie, proliferation) state. ${ }^{130}$ The developmental stage of hair follicles may provide a successful transfollicular immunization path. The difference in hair cycle among various hair follicles leads to variability in immune response to transfollicular immunization.

\section{Animal models employed for study of transfollicular drug-delivery route Hairless animal model}

We know that for the study of the transfollicular pathway, the alternatives of animal models are currently limited. A hairless rodent model may be a best, obvious, and suitable choice for expression of the nonfollicular route; however, these animals only show macroscopic hairlessness and do indeed have defective hair follicles. The skin of hairless rodents typically has a hyperkeratinized SC with enlarged hair follicles, sebaceous glands, epidermis, and dermis, and hair follicles frequently contain cysts. ${ }^{131,132}$ Hairless rodents have histological differences, yet in spite of this, hairless rodents are widely used as models for percutaneous permeation of various chemicals and therapeutics. For some experiments, the hairless rat has been more precisely employed as a follicular model instead of the follicle-free scarring hairless rat skin model. ${ }^{10,78,133}$ Illel and Schaefer ${ }^{134}$ introduced anesthetized rats into water of $60^{\circ} \mathrm{C}$ for 1 minute, followed by removal of the epidermis, which produced follicle-free skin in hairless rats and healing for 3 months. At this point, evaluations of transepidermal water loss showed normal barrier function, and histological examination indicated a total absence of hair follicles and sebaceous glands. The elementary in vitro studies performed by Illel and Schaefer revealed that after 24 hours, the steady-state flux and complete diffusion of $3 \mathrm{H}$-hydrocortisone were 50 -fold greater for hairless rat skin compared to follicle-free hairless rat skin. ${ }^{134}$ In vitro studies showed that penetration of a wide range of therapeutics or chemicals, such as tritiated caffeine, niflumic acid, and $p$-aminobenzoic acid, was about threefold less through a follicle-free model compared to the hairless rat skin model. ${ }^{11}$ Hueber et al supported these determinations with in vivo studies using radiolabeled substances like hydrocortisone, progesterone, and estradiol. The overall outcome of these experiments was that follicular transport occurs, especially via sebaceous glands, and is significant for various topically applied substances. ${ }^{10}$

\section{Follicle-free area of guinea pig skin model}

The hair follicles and sebaceous glands are totally absent in the skin at the back of guinea pig ears, and due to this it is assumed to be a potential model that excludes follicular routes. However, this is an extremely small surface area 
at this site, so investigations are limited and site-specific lipid-composition variability is possible from other sites. Wahlberg employed measurements of surface-radiation disappearance to quantify in vitro and in vivo percutaneous absorption by the application of aqueous and organic mercuric chloride and sodium chloride solutions, which were employed on hairy and follicle-free guinea pig skin. Although differences found in this study were not clear, it should be mentioned that systemic absorption was not measured. ${ }^{135}$

\section{Syrian hamster-ear model}

The ventral side of the Syrian hamster ear contains sebaceous glands in large numbers. Therefore, it is used as a model for sebaceous glands, which act as depot sites. This model, developed by Plewig and Luderschmidt, is based on the fact that the Syrian hamster ear is structurally similar to human sebaceous glands. ${ }^{136}$ Matias and Orentreich developed a method for application of formulation to the ventral surface of the ear. ${ }^{137}$ After the application of formulation at a specific time point, the test animal is killed and the ear is stratified into several anatomical layers to permit scraping of sebaceous contents. These scraped sebaceous components can be quantitatively evaluated by various methods that depend on the employed chemical or permeant. Several molecules in different vehicles, mostly liposomal preparations, have been observed to be absorbed in considerable quantity into the hamster ear via sebaceous glands. ${ }^{138,139}$

\section{Macaque monkey model}

The ideal animal model for clearly determining the contributions of the SC and follicular path remains elusive. At present, the study of an animal model with absolute and completely developed hair follicles may be the best choice. The macaque monkey may be one of the most physiologically accurate models, particularly for studying follicular drug delivery to treat androgenic baldness. This animal shows species-specific frontal scalp baldness that coincides with puberty. These models may be particularly relevant for the analysis of human androgenic alopecia, since the hormonal and genetic factors that cause baldness closely parallel those inducing baldness in humans. Uno and Kurata determined that when the hypertrichotic drugs minoxidil and diazoxide were topically applied, it caused significant enlargement of follicles and regrowth of hair in bald macaques. In a different evaluation, topical use of an antiandrogen drug that inhibits the enzyme $5 \alpha$-reductase provided prevention of baldness in preadolescent macaques. ${ }^{140,141}$

\section{Conclusion}

It can be concluded that drug delivery via the transfollicular route is a promising concept, but it needs molecular exploration to establish better therapeutic exploitation. It appears that the transfollicular delivery route is quite complex in nature, and transportation of the drug via appendages may be modulated by an array of different variables. To date, the majority of experiments in this field have been attempted by applying a variety of drugs, different skin models, many application protocols, and modes of end-point evaluation. As a result, it has become complicated to recognize correlations between different penetrant properties, formulation fabrication, and the degree of follicular permeation. Clearly, further research is required to be carried out on a more systematic and methodical basis. This should allow recognition of the function of the various modulator parameters in transfollicular absorption, to ease the optimization process.

More precisely, it is a need to make a clear demarcation of purpose while using transfollicular route. Transfollicular route is more suitable for systemic drug delivery, where they act as shunts, while it contributes insignificantly in local therapy. The most suitable technique for the former application may be utilized for newer in vitro methodologies, ie, sebum-discharge systems and the skin-sandwich system. These approaches have not yet been widely applied, but their quantitative analysis can help simplify the role of follicles in transdermal drug delivery. These studies should be applied in combination with emerging imaging techniques reported herein. However, in vivo studies are still warranted for both local and systemic follicular applications, because of compromised outcomes of in vitro approaches owing to follicular shaft collapse and/or elimination of the perifollicular circulation. Another hurdle in this area concerns the contribution of sebum, its physicochemical characteristics, and the behavior of sebum-drug interactions. Further, improvements can be attempted in this field by synthesis of synthetic sebum and characterizing its properties, especially in respect to the solubility profile and diffusion rates of several drug molecules.

\section{Disclosure}

The authors report no conflicts of interest in this work.

\section{References}

1. Scheuplein RJ. Mechanism of percutaneous absorption. II. Transient diffusion and the relative importance of various routes of skin penetration. J Invest Dermatol. 1967;48:79-88.

2. Rutherford T, Black J. The use of autoradiography to study the localization of germicides in skin. Br J Dermatol. 1969;81:75-87.

3. Tur E, Maibach H, Guy R. Percutaneous penetration of methyl nicotinate at three anatomic sites: evidence for an appendageal contribution to transport? Skin Pharmacol Physiol. 1991;4:230-234. 
4. Wester RC, Maibach HI. Regional variation in percutaneous absorption. Drugs Pharm Sci. 1999;97:107-116.

5. Bolzinger MA, Briançon S, Pelletier J, Chevalier Y. Penetration of drugs through skin, a complex rate-controlling membrane. Curr Opin Colloid Interface Sci. 2012;17:156-165.

6. Lauer AC, Lieb LM, Ramachandran C, Flynn GL, Weiner ND. Transfollicular drug delivery. Pharm Res. 1995;12:179-186.

7. Lademann J, Otberg N, Richter H, et al. Investigation of follicular penetration of topically applied substances. Skin Pharmacol Appl Skin Physiol. 2000;14:17-22.

8. Essa EA, Bonner MC, Barry BW. Human skin sandwich for assessing shunt route penetration during passive and iontophoretic drug and liposome delivery. J Pharm Pharmacol. 2002;54:1481-1490.

9. Grams YY, Whitehead L, Cornwell P, Bouwstra JA. Time and depth resolved visualisation of the diffusion of a lipophilic dye into the hair follicle of fresh unfixed human scalp skin. $J$ Control Release. 2004;98:367-378.

10. Hueber F, Wepierre J, Schaefer H. Role of transepidermal and transfollicular routes in percutaneous absorption of hydrocortisone and testosterone: in vivo study in the hairless rat. Skin Pharmacol. 1992;5: 99-107.

11. Illel B, Schaefer H, Wepierre J, Doucet O. Follicles play an important role in percutaneous absorption. J Pharm Sci. 1991;80:424-427.

12. Rolland A, Wagner N, Chatelus A, Shroot B, Schaefer H. Site-specific drug delivery to pilosebaceous structures using polymeric microspheres. Pharm Res. 1993;10:1738-1744.

13. Montagna W. The Structure and Function of Skin. 3rd ed. New York: Academic Press; 1974.

14. Jain A, Jain P, Kurmi J. Novel strategies for effective transdermal drug delivery: a review. Crit Rev Ther Drug Carrier Syst. 2014;31:219-272.

15. Gauglitz GG, Schauber J. Skin: architecture and function. In: Kamolz LP, Lumenta DB, editors. Dermal Replacements in General, Burn, and Plastic Surgery: Tissue Engineering in Clinical Practice. Heidelberg: Springer; 2013:1-11.

16. Walters KA, Roberts MS. The structure and function of skin. Drugs Pharm Sci. 2002;119:1-40.

17. Washington N, Washington C, Wilson C. Physiological Pharmaceutics: Barriers to Drug Absorption. 2nd ed. London: Taylor \& Francis; 2000.

18. Naik A, Kalia YN, Guy RH. Transdermal drug delivery: overcoming the skin's barrier function. Pharm Sci Technol Today. 2000;3:318-326.

19. Cevc G. Lipid vesicles and other colloids as drug carriers on the skin. Adv Drug Deliv Rev. 2004;56:675-711.

20. Chourasia R, Jain SK. Drug targeting through pilosebaceous route. Curr Drug Targets. 2009;10:950-967.

21. Rancan F, Afraz Z, Combadiere B, Blume-Peytavi U, Vogt A. Hair follicle targeting with nanoparticles. In: Nasir A, Friedman A, Wang S, editors. Nanotechnology in Dermatology. Heidelberg: Springer; 2012:95-107.

22. Whiting DA. Histology of normal hair. In: Hordinsky M, Sawaya ME, Scher RK, editors. Atlas of Hair and Nails. London: Churchill Livingstone; 1999:9-18.

23. Poblet E, Ortega F, Jiménez F. The arrector pili muscle and the follicular unit of the scalp: a microscopic anatomy study. Dermatol Surg. 2002;28:800-803.

24. Rogers G. Hair follicle differentiation and regulation. Int J Dev Biol. 2004; 48:163-170.

25. Meidan VM, Bonner MC, Michniak BB. Transfollicular drug deliveryis it a reality? Int J Pharm. 2005;306:1-14.

26. Krause K, Foitzik K. Biology of the hair follicle: the basics. Semin Cutan Med Surg. 2006;25:2-10.

27. Hordinsky M. Advances in hair diseases. Adv Dermatol. 2008;24: 245-259.

28. Meidan VM, Touitou E. Treatments for androgenetic alopecia and alopecia areata. Drugs. 2001;61:53-69.

29. Clarys P, Barel A. Quantitative evaluation of skin surface lipids. Clin Dermatol. 1995;13:307-321.
30. Osborne D, Hatzenbuhler D. The influence of skin surface lipids on topical formulations. Drugs Pharm Sci. 1990;42:69-86.

31. Piérard-Franchimont C, Piérard G, Kligman A. Seasonal modulation of sebum excretion. Dermatology. 1990;181:21-22.

32. Knorr F, Lademann J, Patzelt A, Sterry W, Blume-Peytavi U, Vogt A. Follicular transport route - research progress and future perspectives. Eur J Pharm Biopharm. 2009;71:173-180.

33. Vogt A, Hadam S, Heiderhoff M, et al. Morphometry of human terminal and vellus hair follicles. Exp Dermatol. 2007;16:946-950.

34. Tobin DJ. Biochemistry of human skin - our brain on the outside. Chem Soc Rev. 2006;35:52-67.

35. Patzelt A, Knorr F, Blume-Peytavi U, Sterry W, Lademann J. Hair follicles, their disorders and their opportunities. Drug Discov Today Dis Mech. 2008;5:e173-e181.

36. Kertész Z, Szikszai Z, Pelicon P, Simčič J, Telek A, Bíró T. Ion beam microanalysis of human hair follicles. Nucl Instrum Methods Phys Res B. 2007;260:218-221.

37. Otberg N, Richter H, Schaefer H, Blume-Peytavi U, Sterry W, Lademann J. Variations of hair follicle size and distribution in different body sites. J Invest Dermatol. 2004;122:14-19.

38. Lademann J, Weigmann HJ, Rickmeyer C, et al. Penetration of titanium dioxide microparticles in a sunscreen formulation into the horny layer and the follicular orifice. Skin Pharmacol Appl Skin Physiol. 1998;12:247-256.

39. Otberg N, Teichmann A, Rasuljev U, Sinkgraven R, Sterry W, Lademann J. Follicular penetration of topically applied caffeine via a shampoo formulation. Skin Pharmacol Physiol. 2007;20:195-198.

40. Schaefer $\mathrm{H}$, Lademann J. The role of follicular penetration: a differential view. Skin Pharmacol Appl Skin Physiol. 2000;14:23-27.

41. Williams HC, Dellavalle RP, Garner S. Acne vulgaris. Lancet. 2012;379:361-372.

42. James WD, Berger T, Elston D. Andrews' Diseases of the Skin: Clinical Dermatology. 12th ed. Philadelphia: Elsevier; 2015.

43. Teichmann A, Otberg N, Jacobi U, Sterry W, Lademann J. Follicular penetration: development of a method to block the follicles selectively against the penetration of topically applied substances. Skin Pharmacol Physiol. 2005;19:216-223.

44. Ossadnik M, Czaika V, Teichmann A, et al. Differential stripping: introduction of a method to show the penetration of topically applied antifungal substances into the hair follicles. Mycoses. 2007;50:457-462.

45. Lademann J, Richter H, Schaefer U, et al. Hair follicles - a long-term reservoir for drug delivery. Skin Pharmacol Physiol. 2006;19:232-236.

46. Thielitz A, Helmdach M, Röpke EM, Gollnick H. Lipid analysis of follicular casts from cyanoacrylate strips as a new method for studying therapeutic effects of antiacne agents. Br J Dermatol. 2001;145: $19-27$.

47. Toll R, Jacobi U, Richter H, Lademann J, Schaefer H, BlumePeytavi U. Penetration profile of microspheres in follicular targeting of terminal hair follicles. J Invest Dermatol. 2004;123:168-176.

48. Alvarez-Román R, Naik A, Kalia Y, Guy RH, Fessi H. Skin penetration and distribution of polymeric nanoparticles. $J$ Control Release. 2004;99:53-62.

49. Shim J, Kang HS, Park WS, Han SH, Kim J, Chang IS. Transdermal delivery of mixnoxidil [sic] with block copolymer nanoparticles. $J$ Control Release. 2004;97:477-484.

50. Illel B. Formulation for transfollicular drug administration: some recent advances. Crit Rev Ther Drug Carrier Syst. 1997;14:207-219.

51. Domashenko A, Gupta S, Cotsarelis G. Efficient delivery of transgenes to human hair follicle progenitor cells using topical lipoplex. Nat Biotechnol. 2000;18:420-423.

52. Mordon S, Sumian C, Devoisselle JM. Site-specific methylene blue delivery to pilosebaceous structures using highly porous nylon microspheres: an experimental evaluation. Lasers Surg Med. 2003;33: $119-125$.

53. Münster U, Nakamura C, Haberland A, et al. RU 58841-myristate prodrug development for topical treatment of acne and androgenetic alopecia. Pharmazie. 2005;60:8-12. 
54. Meidan V, Docker M, Walmsley A, Irwin W. Low intensity ultrasound as a probe to elucidate the relative follicular contribution to total transdermal absorption. Pharm Res. 1998;15:85-92.

55. Motwani M, Rhein LD, Zatz JL. Differential scanning calorimetry studies of sebum models. J Cosmet Sci. 2001;52:211-224.

56. Musiał W, Kubis A. Preliminary assessment of alginic acid as a factor buffering triethanolamine interacting with artificial skin sebum. Eur $J$ Pharm Biopharm. 2003;55:237-240.

57. Motwani MR, Rhein LD. Influence of vehicles on the phase transitions of. J Cosmet Sci. 2002;53:35-42.

58. Motwani M, Rhein L, Zatz J. Deposition of salicylic acid into hamster sebaceous glands. J Cosmet Sci. 2004;55:519-531.

59. Hoffman RM. Gene and stem cell therapy of the hair follicle. Methods Mol Biol. 2005;289:437-448.

60. Barry B. Action of skin penetration enhancers - the lipid protein partitioning theory. Int J Cosmet Sci. 1988;10:281-293.

61. Oesch F, Fabian E, Oesch-Bartlomowicz B, Werner C, Landsiedel R. Drug-metabolizing enzymes in the skin of man, rat, and pig. Drug Metab Rev. 2007;39:659-698.

62. Erdogan M, Wright JR Jr, McAlister VC. Liposomal tacrolimus lotion as a novel topical agent for treatment of immune-mediated skin disorders: experimental studies in a murine model. $\mathrm{Br} J$ Dermatol. 2002;146:964-967.

63. Agarwal R, Katare O, Vyas S. Preparation and in vitro evaluation of liposomal/niosomal delivery systems for antipsoriatic drug dithranol. Int J Pharm. 2001;228:43-52.

64. Pierre MB, Tedesco AC, Marchetti JM, Bentley MV. Stratum corneum lipids liposomes for the topical delivery of 5-aminolevulinic acid in photodynamic therapy of skin cancer: preparation and in vitro permeation study. BMC Dermatol. 2001;1:5.

65. Touitou E, Levi-Schaffer F, Dayan N, Alhaique F, Riccieri F. Modulation of caffeine skin delivery by carrier design: liposomes versus permeation enhancers. Int J Pharm. 1994;103:131-136.

66. Guo J, Ping Q, Sun G, Jiao C. Lecithin vesicular carriers for transdermal delivery of cyclosporin A. Int J Pharm. 2000;194:201-207.

67. Mezei M, Gulasekharam V. Liposomes - a selective drug delivery system for the topical route of administration: gel dosage form.J Pharm Pharmacol. 1982;34:473-474.

68. Fang JY, Hong CT, Chiu WT, Wang YY. Effect of liposomes and niosomes on skin permeation of enoxacin. Int J Pharm. 2001;219: 61-72.

69. Dayan N, Touitou E. Carriers for skin delivery of trihexyphenidyl $\mathrm{HCl}$ : ethosomes vs liposomes. Biomaterials. 2000;21:1879-1885.

70. Fresta M, Puglisi G. Corticosteroid dermal delivery with skin-lipid liposomes. J Control Release. 1997;44:141-151.

71. Betz G, Nowbakht P, Imboden R, Imanidis G. Heparin penetration into and permeation through human skin from aqueous and liposomal formulations in vitro. Int J Pharm. 2001;228:147-159.

72. Knepp VM, Hinz RS, Szoka FC, Guy RH. Controlled drug release from a novel liposomal delivery system. I. Investigation of transdermal potential. J Control Release. 1987;5:211-221.

73. Ferreira LS, Ramaldes GA, Nunan EA, Ferreira LA. In vitro skin permeation and retention of paromomycin from liposomes for topical treatment of the cutaneous leishmaniasis. Drug Dev Ind Pharm. 2004; 30:289-296

74. Raghavachari N, Fahl WE. Targeted gene delivery to skin cells in vivo: a comparative study of liposomes and polymers as delivery vehicles. J Pharm Sci. 2002;91:615-622.

75. Han I, Kim M, Kim J. Enhanced transfollicular delivery of adriamycin with a liposome and iontophoresis. Exp Dermatol. 2004;13: 86-92.

76. Fang JY, Yu SY, Wu PC, Huang YB, Tsai YH. In vitro skin permeation of estradiol from various proniosome formulations. Int J Pharm. 2001;215:91-99.

77. Vora B, Khopade AJ, Jain N. Proniosome based transdermal delivery of levonorgestrel for effective contraception. J Control Release. 1998; 54:149-165.
78. Bamba FL, Wepierre J. Role of the appendageal pathway in the percutaneous absorption of pyridostigmine bromide in various vehicles. Eur J Drug Metab Pharmacokinet. 1993;18:339-348.

79. Dokka S, Cooper SR, Kelly S, Hardee GE, Karras JG. Dermal delivery of topically applied oligonucleotides via follicular transport in mouse skin. J Invest Dermatol. 2005;124:971-975.

80. Wu H, Ramachandran C, Bielinska AU, et al. Topical transfection using plasmid DNA in a water-in-oil nanoemulsion. Int $J$ Pharm. 2001;221:23-34.

81. Wu H, Ramachandran C, Weiner ND, Roessler BJ. Topical transport of hydrophilic compounds using water-in-oil nanoemulsions. Int $J$ Pharm. 2001;220:63-75.

82. Jain A, Gulbake A, Jain A, Shilpi S, Hurkat P, Jain SK. Dual drug delivery using "smart" liposomes for triggered release of anticancer agents. J Nanopart Res. 2013;15:1-12.

83. Jain A, Jain SK. Multipronged, strategic delivery of paclitaxeltopotecan using engineered liposomes to ovarian cancer. Drug Dev Ind Pharm. Epub 2015 Jun 2.

84. Balsari AL, Morelli D, Menard S, Veronesi U, Colnaghi MI. Protection against doxorubicin-induced alopecia in rats by liposome-entrapped monoclonal antibodies. FASEB J. 1994;8:226-230.

85. Li L, Hoffman RM. Topical liposome delivery of molecules to hair follicles in mice. J Dermatol Sci. 1997;14:101-108.

86. Niemiec SM, Ramachandran C, Weiner N. Influence of nonionic liposomal composition on topical delivery of peptide drugs into pilosebaceous units: an in vivo study using the hamster ear model. Pharm Res. 1995;12:1184-1188.

87. Ciotti SN, Weiner N. Follicular liposomal delivery systems. J Liposome Res. 2002;12:143-148

88. Verma DD, Verma S, McElwee KJ, Freyschmidt-Paul P, Hoffman R, Fahr A. Treatment of alopecia areata in the DEBR model using cyclosporin A lipid vesicles. Eur J Dermatol. 2004;14:332-338.

89. Meidan VM, Cohen JS, Amariglio N, Hirsch-Lerner D, Barenholz Y. Interaction of oligonucleotides with cationic lipids: the relationship between electrostatics, hydration and state of aggregation. Biochim Biophys Acta. 2000;1464:251-261.

90. Meidan VM, Glezer J, Amariglio N, Cohen JS, Barenholz Y. Oligonucleotide lipoplexes: the influence of oligonucleotide composition on complexation. Biochim Biophys Acta. 2001;1568:177-182.

91. Jain A, Jain SK. Ligand-mediated drug-targeted liposomes. In: Samad A, Beg S, Nazish I, editors. Liposomal Delivery Systems: Advances and Challenges. London: Future Science; 2016: 144-158.

92. Lieb LM, Liimatta AP, Bryan RN, Brown BD, Krueger GG. Description of the intrafollicular delivery of large molecular weight molecules to follicles of human scalp skin in vitro. J Pharm Sci. 1997;86: 1022-1029

93. Uitto OD, White HS. Electroosmotic pore transport in human skin. Pharm Res. 2003;20:646-652.

94. Junginger HE. Iontophoretic delivery of apomorphine: from in-vitro modelling to the Parkinson patient. Adv Drug Deliv Rev. 2002;54: S57-S75.

95. Kanikkannan N. Iontophoresis-based transdermal delivery systems. BioDrugs. 2002;16:339-347

96. Kalia YN, Naik A, Garrison J, Guy RH. Iontophoretic drug delivery. Adv Drug Deliv Rev. 2004;56:619-658.

97. Kaushik S, Hord AH, Denson DD, et al. Lack of pain associated with microfabricated microneedles. Anesth Analg. 2001;92:502-504.

98. Prausnitz MR. Microneedles for transdermal drug delivery. Adv Drug Deliv Rev. 2004;56:581-587.

99. Prausnitz MR, Mikszta JA, Cormier M, Andrianov AK. Microneedlebased vaccines. Curr Top Microbiol Immunol. 2009;333:369-393.

100. Verma D, Fahr A. Investigation on the efficacy of a new device for substance deposition into deeper layers of the skin: Dermaroller. Institut für Pharmazeutische Technologie und Biopharmazie, PhilippsUniversität Marburg. 2001. Available from: http://www.hair2go.jp/ derma_evalu01.pdf. 
101. Clementoni MT, Munavalli GS. Photodynamic photorejuvenation of the face with a combination of microneedling, red light, and broadband pulsed light. Lasers Surg Med. 2010;42:150-159.

102. Budamakuntla L, Loganathan E, Suresh DH, et al. A randomised, open-label, comparative study of tranexamic acid microinjections and tranexamic acid with microneedling in patients with melasma. J Cutan Aesthet Surg. 2013;6:139-143.

103. Dhurat R, Sukesh M, Avhad G, Dandale A, Pal A, Pund P. A randomized evaluator blinded study of effect of microneedling in androgenetic alopecia: a pilot study. Int J Trichology. 2013;5:6-11.

104. Chandrashekar B, Yepuri V, Mysore V. Alopecia areata - successful outcome with microneedling and triamcinolone acetonide. J Cutan Aesthet Surg. 2014;7:63-64.

105. Torezan L, Chaves Y, Niwa A, Sanches JA, Festa-Neto C, Szeimies RM. A pilot split-face study comparing conventional methyl aminolevulinatephotodynamic therapy (PDT) with microneedling-assisted PDT on actinically damaged skin. Dermatol Surg. 2013;39:1197-1201.

106. Tabbakhian M, Tavakoli N, Jaafari MR, Daneshamouz S. Enhancement of follicular delivery of finasteride by liposomes and niosomes 1 . In vitro permeation and in vivo deposition studies using hamster flank and ear models. Int J Pharm. 2006;323:1-10.

107. Namdeo A, Jain N. Niosomes as drug carriers. Indian J Pharm Sci. 1996;58:41-46.

108. Al-Saidan S, Krishnaiah Y, Chandrasekhar D, et al. Formulation of an HPMC gel drug reservoir system with ethanol-water as a solvent system and limonene as a penetration enhancer for enhancing in vitro transdermal delivery of nicorandil. Skin Pharmacol Physiol. 2004;17:310-320.

109. Lademann J, Richter H, Teichmann A, et al. Nanoparticles - an efficient carrier for drug delivery into the hair follicles. Eur J Pharm Biopharm. 2007;66:159-164.

110. Gloor M. How do dermatological vehicles influence the horny layer? Skin Pharmacol Physiol. 2004;17:267-273.

111. Schaller M, Laude J, Bodewaldt H, Hamm G, Korting H. Toxicity and antimicrobial activity of a hydrocolloid dressing containing silver particles in an ex vivo model of cutaneous infection. Skin Pharmacol Physiol. 2004; 17:31-36.

112. Nicoli S, Amoretti V, Colombo P, Santi P. Bioadhesive transdermal film containing caffeine. Skin Pharmacol Physiol. 2004;17:119-123.

113. Teichmann A, Jacobi U, Ossadnik M, et al. Differential stripping: determination of the amount of topically applied substances penetrated into the hair follicles. J Gen Intern Med. 2005;20:264-269.

114. Müller RH, Radtke M, Wissing SA. Solid lipid nanoparticles (SLN) and nanostructured lipid carriers (NLC) in cosmetic and dermatological preparations. Adv Drug Deliv Rev. 2002;54:S131-S155.

115. Liu KS, Wen CJ, Yen TC, et al. Combined strategies of apomorphine diester prodrugs and nanostructured lipid carriers for efficient brain targeting. Nanotechnology. 2012;23:095103.

116. El Maghraby GM, Williams AC, Barry BW. Skin hydration and possible shunt route penetration in controlled estradiol delivery from ultradeformable and standard liposomes. J Pharm Pharmacol. 2001;53:1311-1322.

117. Barry B. Drug delivery routes in skin: a novel approach. Adv Drug Deliv Rev. 2002;54:S31-S40.

118. Grams YY,Alaruikka S, Lashley L, Caussin J, Whitehead L, Bouwstra JA. Permeant lipophilicity and vehicle composition influence accumulation of dyes in hair follicles of human skin. Eur J Pharm Sci. 2003;18:329-336.

119. Grams YY, Whitehead L, Cornwell P, Bouwstra JA. On-line visualization of dye diffusion in fresh unfixed human skin. Pharm Res. 2004;21:851-859.

120. Caspers P, Lucassen G, Puppels G. Combined in vivo confocal Raman spectroscopy and confocal microscopy of human skin. Biophys J. 2003;85:572-580.
121. Glenn GM, Taylor DN, Li X, Frankel S, Montemarano A, Alving CR. Transcutaneous immunization: a human vaccine delivery strategy using a patch. Nat Med. 2000;6:1403-1406.

122. Fan H, Lin Q, Morrissey GR, Khavari PA. Immunization via hair follicles by topical application of naked DNA to normal skin. Nat Biotechnol. 1999;17:870-872.

123. Combadière B, Vogt A, Mahé B, et al. Preferential amplification of CD8 effector-T cells after transcutaneous application of an inactivated influenza vaccine: a randomized phase I trial. PloS One. 2010;5: e10818.

124. Mittal A, Raber AS, Schaefer UF, et al. Non-invasive delivery of nanoparticles to hair follicles: a perspective for transcutaneous immunization. Vaccine. 2013;31:3442-3451.

125. Baleeiro RB, Wiesmüller KH, ReiterY, et al. Topical vaccination with functionalized particles targeting dendritic cells. J Invest Dermatol. 2013;133:1933-1941.

126. Gilliam AC, Kremer IB, Yoshida Y, et al. The human hair follicle: a reservoir of $\mathrm{CD} 40+\mathrm{B} 7$-deficient Langerhans cells that repopulate epidermis after UVB exposure. J Invest Dermatol. 1998;110:422-427.

127. Brandner JM, McIntyre M, Kief S, Wladykowski E, Moll I. Expression and localization of tight junction-associated proteins in human hair follicles. Arch Dermatol Res. 2003;295:211-221.

128. Kubo A, Nagao K, Yokouchi M, Sasaki H, Amagai M. External antigen uptake by Langerhans cells with reorganization of epidermal tight junction barriers. J Exp Med. 2009;206:2937-2946.

129. Paus R, Ito N, Takigawa M, Ito T. The hair follicle and immune privilege. J Investig Dermatol Symp Proc. 2003;8:188-194.

130. Hofmann U, Tokura Y, Nishijima T, Takigawa M, Paus R. Hair cycledependent changes in skin immune functions: anagen-associated depression of sensitization for contact hypersensitivity in mice. J Invest Dermatol. 1996;106:598-604.

131. Hanada K, Chiyoya S, Suzuki K, Hashimoto I, Hatayama I. Study of the skin of a new hairless rat mutant. J Dermatol. 1988;15: 257-262.

132. Lauer AC, Elder JT, Weiner ND. Evaluation of the hairless rat as a model for in vivo percutaneous absorption. J Pharm Sci. 1997;86:13-18.

133. Schaefer H, Watts F, Brod J, Illel B. Follicular penetration. In: Scott RC, Guy RH, Hadgraft J, editors. Prediction of Percutaneous Penetration: Methods, Measurements, Modeling. London: IBC Technical Sevices; 1990:163-173.

134. Illel B, Schaefer H. Transfollicular percutaneous absorption: skin model for quantitative studies. Acta Derm Venereol. 1987;68:427-430.

135. Wahlberg JE. Transepidermal or transfollicular absorption? In vivo and in vitro studies in hairy and non-hairy guinea pig skin with sodium $(22 \mathrm{Na})$ and mercuric $(203 \mathrm{Hg})$ chlorides. Acta Derm Venereol. 1968;48:336-344.

136. Plewig G, Luderschmidt C. Hamster ear model for sebaceous glands. J Invest Dermatol. 1977;68:171-176.

137. Matias JR, Orentreich N. The hamster ear sebaceous glands. I. Examination of the regional variation by stripped skin planimetry. $J$ Invest Dermatol. 1983;81:43-46.

138. Lieb LM, Ramachandran C, Egbaria K, Weiner N. Topical delivery enhancement with multilamellar liposomes into pilosebaceous units: I. In vitro evaluation using fluorescent techniques with the hamster ear model. J Invest Dermatol. 1992;99:108-113.

139. Lieb LM, Flynn G, Weiner N. Follicular (pilosebaceous unit) deposition and pharmacological behavior of cimetidine as a function of formulation. Pharm Res. 1994;11:1419-1423.

140. Uno H. Quantitative models for the study of hair growth in vivo. Ann NY Acad Sci. 1991;642:107-124.

141. Uno H, Kurata S. Chemical agents and peptides affect hair growth. J Invest Dermatol. 1993;101:143S-1477S. 


\section{Publish your work in this journal}

Research and Reports in Transdermal Drug Delivery is an international, peer-reviewed, open access online journal publishing original research, study protocols, reviews, editorials and commentaries on all aspects of transdermal drug delivery. Specific topics in the journal include: Laboratory and clinical development of drug delivery systems including preclinical, clinical studies and protocols; Rationale and basic science; Drug

Submit your manuscript here: http://www.dovepress.com/research-and-reports-in-transdermal-drug-delivery-journal delivery via gels, creams or patches; Use of chemical drug penetration enhancers; Patient acceptability studies; and pharmacoeconomic and clinical outcome studies. The manuscript management system is completely online and includes a very quick and fair peer-review system, which is all easy to use. Visit http://www.dovepress.com/ testimonials.php to read real quotes from published authors. 